\title{
Analysis of the energy balance closure over a FLUXNET boreal forest in Finland
}

\author{
J. M. Sánchez ${ }^{1}$, V. Caselles $^{2}$, and E. M. Rubio ${ }^{1,3}$ \\ ${ }^{1}$ Applied Physics Department, School of Industrial Engineering, University of Castilla-La Mancha, Av. España s/n, 02071 \\ Albacete, Spain \\ ${ }^{2}$ Earth Physics and Thermodynamics Department, University of Valencia, C/ Dr. Moliner 50, 46100 Burjassot \\ (Valencia), Spain \\ ${ }^{3}$ Institute of Regional Development, University of Castilla-La Mancha, Av. España s/n, 02071 Albacete, Spain
}

Received: 6 April 2010 - Published in Hydrol. Earth Syst. Sci. Discuss.: 3 May 2010

Revised: 15 July 2010 - Accepted: 26 July 2010 - Published: 6 August 2010

\begin{abstract}
The imbalance in the surface energy budget, when using eddy-covariance techniques to measure turbulent fluxes, is still an unresolved problem. Important progresses have been reported in recent years identifying potential reasons for this lack of energy balance closure. In this paper we focus on the data collected in a FLUXNET boreal forest site in Sodankylä, Finland. Using one month half-hourly data, an average Energy Balance Ratio (EBR) of 0.72 is obtained. The inclusion of the heat storage terms in the energy budget yields an improvement of about $6 \%$ in the total closure. The sensitivity of the energy balance closure to the turbulence intensity is analysed in terms of the friction velocity, and atmospheric stability/instability conditions. Significant better closure is obtained for high values of the friction velocity and unstable conditions. The mismatch in variable footprints for different fluxes is checked by analysing the dependence of the closure on wind direction. The inhomogeneities of the emplacement surrounding the flux tower induce a critical decrease in the EBR of up to $30 \%$ for specific wind directions. After filtering all unfavourable conditions, $\mathrm{EBR}=0.94$. This is a reasonable good result for the energy balance closure. However there is still a $6 \%$ of the available energy unaccounted. Part of this remaining imbalance could be justified as the impossibility of the $30 \mathrm{~min}$ averaging time to capture the low frequency flux contributions, since the closure is improved by a $5 \%$ when the averaging time is expanded to $2 \mathrm{~h}$.
\end{abstract}

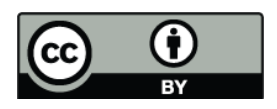

Correspondence to: J. M. Sánchez (juanmanuel.sanchez@uclm.es)

\section{Introduction}

The problem of energy imbalance when measuring turbulent vertical fluxes at some height above the surface has been widely studied in the last few years (Culf et al., 2004; Foken et al., 2006, 2008; Wilson et al., 2002; Tanaka et al., 2008; Barr et al., 2006; Oncley et al., 2007). The eddy-covariance (EC) method has become a standard tool in the study of the surface-atmosphere boundary layer interactions. However, a lack of closure in the surface energy balance of about 10$30 \%$ is traditionally reported when using EC techniques to measure the turbulent fluxes (Wilson et al., 2002; Barr et al., 2006; Gao et al., 2009; Ma et al., 2009; Wen et al., 2009; Su et al., 2009). This imbalance has implications on how energy flux measurements should be interpreted and how these estimates should be compared with model simulations (Twine et al., 2000; Xin et al., 2010; van der Tol et al., 2009; Liu et al., 2010; van der Kwast et al., 2009; Were et al., 2007). Thus, it is imperative to improve our understanding of this problem, as well as to determine possible causes. This is of particular relevance in boreal forest ecosystems since they cover an extension of $11 \%$ of the terrestrial surface and their unique biophysical properties confer these ecosystems potential to impact on the Earth's climate (Baldocchi et al., 1997).

The objective of this paper is to identify and quantify sources of energy imbalance using data registered at one of the FLUXNET sites located in Sodankylä, Finland. In particular, we focus on the dataset collected as part of the Solar Induced Fluorescence Experiment in the summer of 2002 (SIFLEX-2002). With this goal we expect to contribute to the existing literature on the energy balance closure in general, and over forest sites in particular. 
In a forest environment, the surface energy balance is conveniently expressed as:

$R_{n}=H+L E+G+S$

where $R_{n}$ is the net radiation flux $\left(\mathrm{W} \mathrm{m}{ }^{-2}\right), H$ is the sensible heat flux $\left(\mathrm{W} \mathrm{m}^{-2}\right), L E$ is the latent heat flux $\left(\mathrm{W} \mathrm{m}^{-2}\right), G$ is the soil heat flux $\left(\mathrm{W} \mathrm{m}^{-2}\right.$ ), and $S$ is the storage heat flux (W $\mathrm{m}^{-2}$ ). The importance of $S$ is expected to be small in short canopies with minimal biomass; however this term must be maintained for tall, forested sites (McCaughey, 1985). Other minor terms, such as photosynthesis, could be added to Eq. (1). Some authors have illustrated that, on a $30 \mathrm{~min}$ basis, this term can amount up to $1-2 \%$ of the available energy over boreal forests on clear summer days (Blanken et al., 1997). Even in these favourable conditions photosynthesis is negligibly small and can be ignored.

The soil heat flux is measured by heat flux plates placed at a certain depth in the soil to avoid disturbances, such as the loss of contact with the underlying soil or the accumulation of water below the plates. As a consequence, the real value of $G$ is a combination of the flux measured by the plate, $G^{\prime}$, and the heat storage between the ground and the depth of the plate, $\Delta G$ :

$G=G^{\prime}+\Delta G$

The storage term can be significant when we aim to resolve the diurnal cycle over short periods, particularly around sunrise and sunset. Since measurements of biomass heat storage were not available during SIFLEX experiment, in this paper $S$ is obtained as the addition of only the flux divergences between the surface and the EC measurement level, estimated from the change in storage, the EC storage-fluxes $\left(S_{H}\right.$ and $\left.S_{L E}\right)$ :

$S=S_{H}+S_{L E}$

The significance of neglecting the biomass heat storage will be further discussed.

Two different methods are proposed to evaluate energy balance closure. The first method is to derive linear regression coefficients from the ordinary linear regression between the turbulent fluxes against the available energy. A second method is to calculate the energy balance ratio (EBR) (Wilson et al., 2002; Oliphant et al., 2004). To analyse the effect of the storage terms on the total energy balance closure, three versions of the EBR are studied:

$$
\begin{aligned}
\mathrm{EBR}_{1} & =\frac{H+L E}{R_{n}-G^{\prime}} \\
\mathrm{EBR}_{2} & =\frac{H+L E}{R_{n}-G} \\
\mathrm{EBR}_{3} & =\frac{H+L E}{R_{n}-G-S}
\end{aligned}
$$

Table 1. Characteristics of the SIFLEX-2002 study site.

\begin{tabular}{ll}
\hline Features & Value \\
\hline Ecosystem & Scots pine forest \\
Vegetation type & Evergreen needleleaf forest \\
Understorey & $73 \%$ lichens, $12 \%$ mosses, \\
& $15 \%$ small shrubs \\
Soil type & Sand podsol \\
Mean annual temperature, ${ }^{\circ} \mathrm{C}$ & -1.0 \\
Mean annual precipitation, $\mathrm{mm}$ & 499 \\
Vegetation height, $\mathrm{m}$ & 11 \\
Tree density, trunk ha & \\
Diameter at breast height, $\mathrm{cm}$ & 2100 \\
Tree age, yr & 18 \\
Measurement height, $\mathrm{m}$ & $23 \mathrm{~m}$ \\
Leaf area index, $\mathrm{m}^{2} \mathrm{~m}^{-2}$ & 1.37 \\
\hline
\end{tabular}

\section{Experimental site and measurements}

\subsection{Site description}

The present work is based on the data collected in a boreal forest area in Sodankylä, northern Finland. This site $\left(67^{\circ}\right.$ $22^{\prime} \mathrm{N}, 26^{\circ} 38^{\prime} \mathrm{E}, 179 \mathrm{~m}$ above sea level) was established in 2000 as part of the FLUXNET network of eddy covariance sites measuring long-term carbon and energy fluxes (Moreno et al., 2002). It is also one of the reference sites of the Global Energy and Water Cycle Experiment (GEWEX) of the World Climate Research Programme. Table 1 summarises some of the site characteristics. Additional details are given by Moreno et al. (2002), and Sánchez et al. (2009).

\subsection{Instrumental set-up and measurements}

A 48-m height micrometeorological mast was placed at the site. Wind speed and wind direction data were collected by a Vaisala WAA252 anemometer, placed at a height of $23 \mathrm{~m}$. At this same height, sensible and latent heat fluxes, as well as the friction velocity $u^{*}$, were measured with a SATI-3Sx (Applied Technologies Inc.) sonic anemometer and a platinum thermal probe in combination with a closed path, infrared gas analyzer LICOR LI-7000, by using eddy-covariance methodology. Note that the SATI-3 Sx was replaced some time after the experiment by a Metek USA-1 (Aurela et al., 2004).

Half-hourly $H$ and $L E$ values were computed, by the colleagues with the Finish Meteorological Institute (FMI) participating in the experiment, as covariance of the vertical wind speed and the air temperature or vapour density, respectively, sampled at $10 \mathrm{~Hz}$. The EC data acquisition was carried out by in-house programs using the program by McMillen 
(1986) as a basis, but introducing some updates. The 30-min averaging period has been used together with an autoregressive running-mean filter with a $200-\mathrm{s}$ time constant. A double rotation of the coordinate system was performed according to McMillen (1988). A more recent planar fit rotation method has been proposed by Wilczak et al. (2001). However, no significant difference between the resulting turbulent fluxes was observed when applying both rotation methods (Tuovinen et al., 2005).

The lag between the time series resulting from the transport through the inlet tube is taken into account in the on-line calculation of the flux quantities (Aurela et al., 2002). Additional manipulations and corrections were applied to the collected data off-line (Aurela et al., 1998). One of them is related to the suppression of turbulence during calm conditions when the surface layer becomes stable. To avoid this night-time problem original data with $u^{*}<0.2 \mathrm{~m} \mathrm{~s}^{-1}$ was discarded and gaps were then filled by modeled values using the mean diurnal variation method (Falge et al., 2001).

The LI-7000 does not take into account the humidity variations, and thus a partial density correction was performed. Corrections for the systematic flux loss owing to the imperfect properties and setup of the sensors (insufficient response time, sensor separation, damping of the signal in the tubing and averaging over the measurement paths) were formerly performed according to the procedures suggested by Moore (1986) (Aurela et al., 2001). Note that Moore's (1986) proposed correction for aliasing was not included since it is wrong (Horst, 2000).

It has been recently reported by Ibrom et al. (2007) that water flux measurements with closed-path systems may suffer from considerable low-pass filtering (resulting in a flux underestimation) not taken into account by available tube attenuation correction algorithms, as these neglect adsorption/desorption of water vapor to/from the tube walls (Massman and Ibrom, 2008). These authors pointed out that LE flux corrections are also dependent upon humidity. Massman (2000) showed that the magnitude of the corrections for flux loss depends on wind speed and stable/unstable atmospheric conditions. Corrections are less than $6 \%$ for stable conditions and also during unstable conditions if wind speeds are greater than $1 \mathrm{~m} \mathrm{~s}^{-1}$, whereas correction may reach almost $40 \%$ for unstable conditions and low wind speeds.

Air temperature, $T_{a}$, and humidity, $q$, were measured at different levels $(3,18$, and $23 \mathrm{~m}$ ) using Vaisala HMP 45 temperature-humidity probes. These measurements were used to calculate $S_{H}$ and $S_{L E}$ by integration of the temperature-humidity profiles (Barr et al., 2006):

$$
\begin{aligned}
& S_{H}=\int_{0}^{z} \rho C_{p} \frac{d T_{a}}{d t} d z \\
& S_{L E}=\int_{0}^{z} \rho \lambda \frac{d q}{d t} d z
\end{aligned}
$$

where $\rho$ is the density of moist air, $C_{p}$ is the specific heat of moist air, and $\lambda$ is the latent heat of evaporation.

A net radiometer Q-7, REBS was placed at the top of the tower $(48 \mathrm{~m})$ to measure the net radiation flux. Some experiments have recently shown the low accuracy of this particular sensor when compared to other (Brotzge and Duchon, 2000; Cobos and Baker, 2003; Kohsiek et al., 2007). Kohsiek et al. (2007) suggest the net radiation is preferably to be inferred from its four components, rather than measured directly. Unfortunately, only three of the components were measured during the SIFLEX campaign and net radiation calculation is not possible. The effect of a hypothetical deviation in the measured $R_{n}$ values will be discussed in Sect. 3.2.

The soil heat flux $G^{\prime}$ was measured using a HFT3 (Campbell Scientific) soil heat flux plate at $7 \mathrm{~cm}$ depth. Soil temperature was measured at 2, 5, 10,20,50, and $100 \mathrm{~cm}$ depth by using a set of thermocouples, and volumetric soil moisture at $5,10,20,30$, and $50 \mathrm{~cm}$ through Delta-T TDR-probes. The heat stored, $\Delta G$, in the soil profile above the plate located at a depth " $d$ ", was computed from the temporal change in soil temperature $\left(\Delta T_{S}\right)$ over the output interval " $t$ ", soil water content $\left(\theta_{v}\right)$, and ancillary data such as the bulk density $\left(\rho_{b}\right)$ or the specific heat of the dry soil $\left(C_{d}\right)$ (Tanaka et al., 2008):

$$
\begin{aligned}
& \Delta G=\frac{\Delta T_{s} C_{s} d}{t} \\
& C_{s}=\rho_{b}\left(C_{d}+\rho_{w} \theta_{v} C_{w}\right)
\end{aligned}
$$

where $\rho_{w}$ is the density of water and $C_{w}$ is the heat capacity of water.

In this paper we focus on the data collected during the SIFLEX-2002 project, from 5 May to 9 June of 2002.

\section{Results and discussion}

\subsection{Energy balance closure}

The energy balance closure was evaluated for the whole halfhourly dataset. A total of 1270 valid data points were considered. For this study no distinction was established between day-time and nigh-time data since solar radiation was rarely null during the experiment. Figure 1 shows the plots of the linear regressions between the turbulent heat flux $(H+L E)$ and the available energy. When only fluxes directly measured by the sensors are considered, and thus storage terms are neglected, a slope of 0.75 and an intercept of $15 \mathrm{~W} \mathrm{~m}^{-2}$ are obtained (Fig. 1a). In Fig. 1b, the heat storage in the soil is included in the available energy. An increase of $6 \%$ is observed in the slope of the linear regression, as well as a decrease of $8 \mathrm{~W} \mathrm{~m}^{-2}$ in the intercept. An additional increase of $3 \%$ is observed when the EC storage-fluxes are considered. Similar results are reproduced in terms of the energy balance ratios, EBR, defined previously (see Table 3). Wen et al. (2009), using data from the LOPEX05 (Loess Plateau mesa region land 


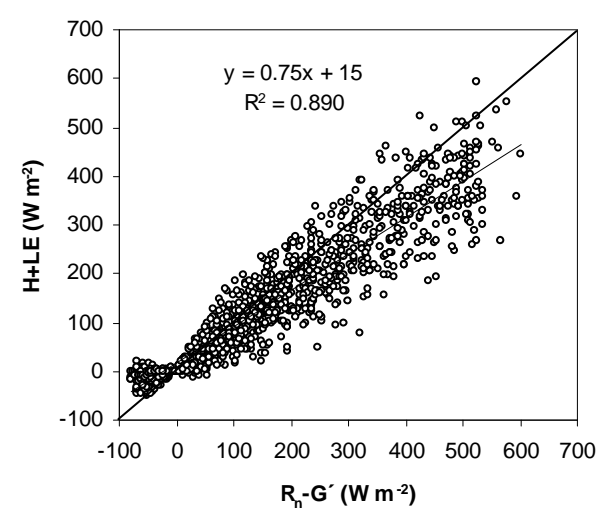

(a)

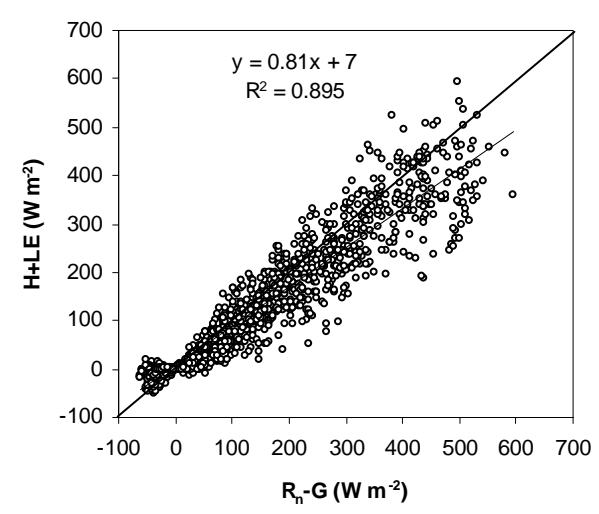

(b)

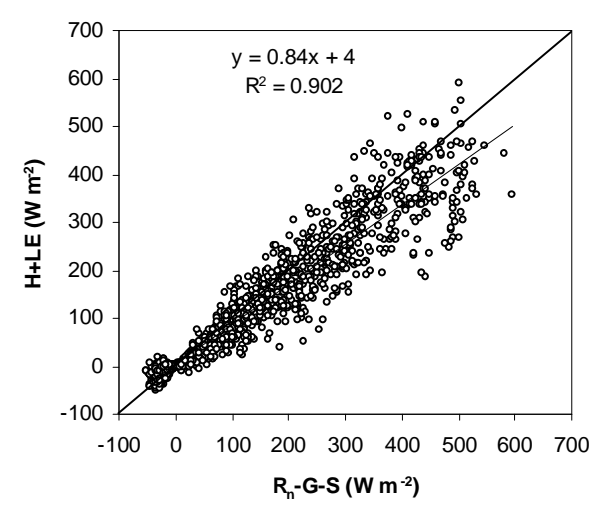

(c)

Fig. 1. Relationships between half-hourly data turbulent heat flux $H+L E$ and available energy: (a) $R_{n}-\mathrm{G}^{\prime}$, (b) $R_{n}-\mathrm{G}$, and (c) $R_{n}-\mathrm{G}-\mathrm{S}$.

surface process field Experiment 2005), showed that the contributions from heat storage in the soil and the atmospherecanopy layer between the Sonic anemometer and land surface were about $11 \%$ and $3 \%$, respectively. Gao et al. (2009) were also aware of this problem and reported an increase of about $20 \%$ in the slope of the linear regression when includ-

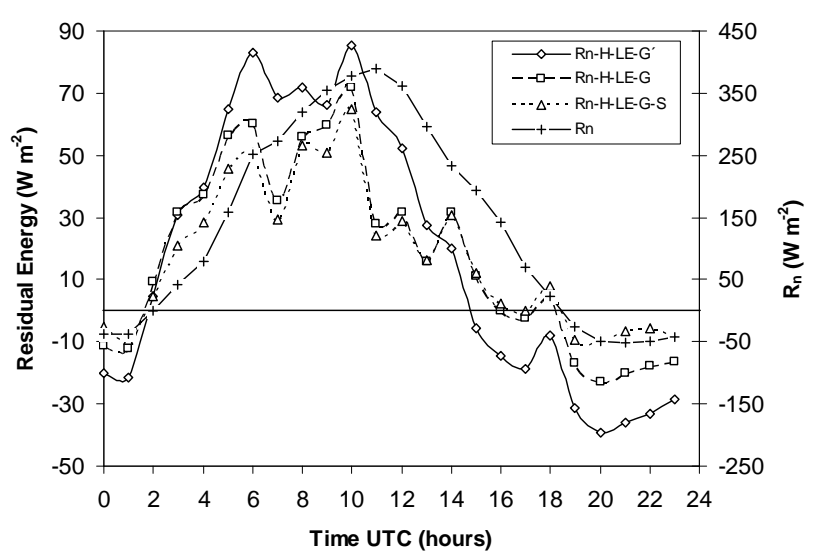

(a)

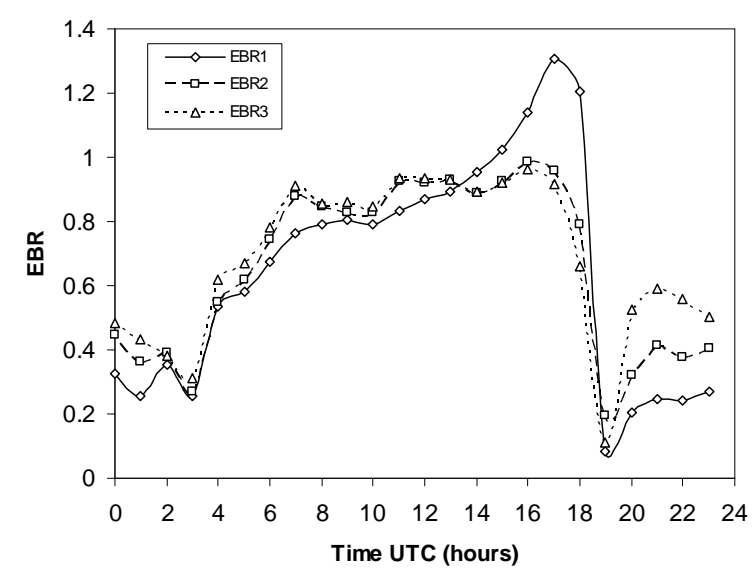

(b)

Fig. 2. Average diurnal variation of: (a) the residual energy in principal axis and net radiation in secondary axis, (b) the energy balance ratio.

ing the soil heat storage in a steppe prairie in Inner Mongolia.

An average imbalance of about $18 \%$ still remained once all the storage terms were considered. Wilson et al. (2002), in a comprehensive study across 22 sites in FLUXNET, reported values of slopes and intercepts ranging from 0.53 to 0.99 , and from -33 to $37 \mathrm{~W} \mathrm{~m}^{-2}$, respectively, and EBR ranging from 0.39 to 1.69 . Wu et al. (2007) showed a slope of 0.86 on a $30 \mathrm{~min}$ basis in a mixed broadleaved-pine forest in Northeastern China. Using data from the Tibetan Observation and Research Platform (TORP), Ma et al. (2009) reported energy closures of 0.70 in summer and 0.92 in winter over the flat prairie on the northern Tibetan Plateau. Liu et al. (2010) observed an EBR value of 0.85 in an alfalfa field located in a semi-arid area in China. Also in China, and under similar semi-arid conditions, an EBR value of 0.80 was found by Xin and Liu (2010) in a maize crop. Were et al. (2007) showed EBR values close to 0.90 over shrub and herbaceous patches in a dry valley on southeast Spain. 


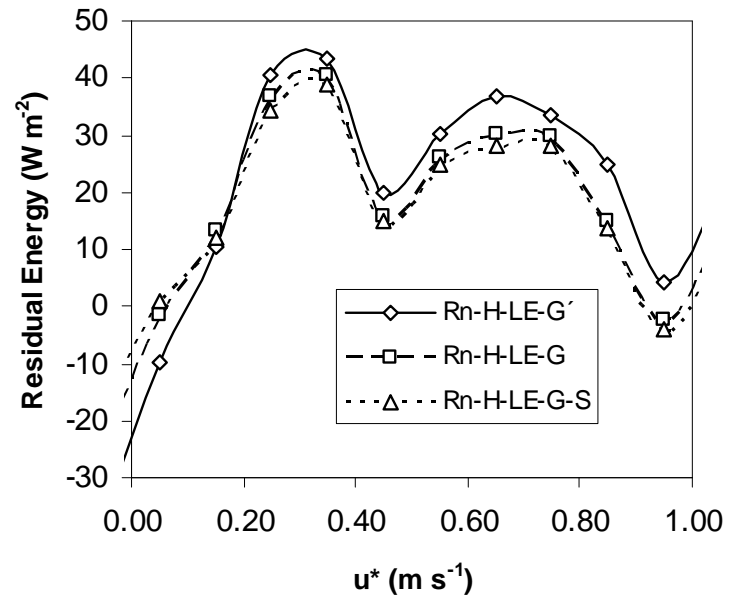

(a)

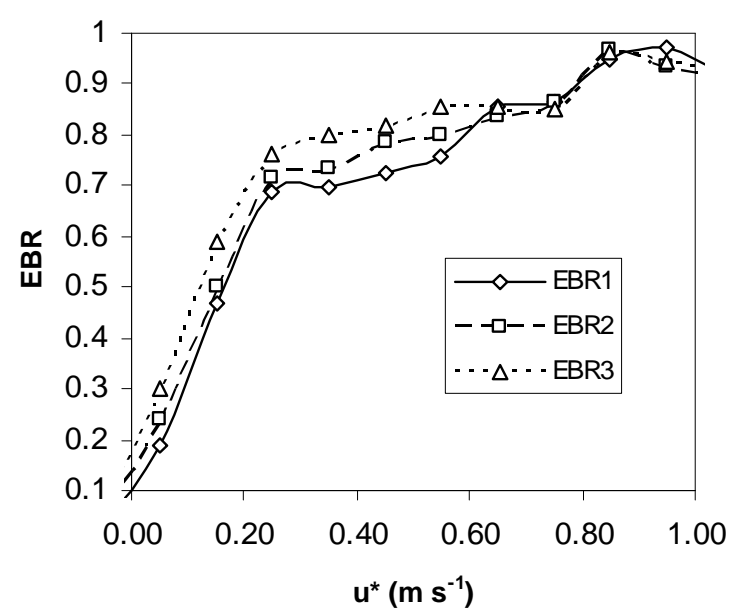

(b)

Fig. 3. Effect of the friction velocity $\mathrm{u}^{*}$ on: (a) the residual energy, (b) the energy balance ratio. Values indicate averages in each range of $u^{*}$.

Some authors (Foken et al., 2006; Cava et al., 2008; Wilson et al., 2002) have discussed possible causes for this lack of energy balance since it is clear that the problem cannot be described only as an effect of statistically distributed measuring errors. These causes include: (i) mismatch in source areas for the terms in Eq. (1), (ii) systematic bias in instrumentation, (iii) neglected energy sinks, (iv) loss of low and/or high frequency contributions to turbulent fluxes, etc. To determine potential sources of error for this imbalance, in the following sections we analyse its diurnal evolution, the effect of the friction velocity and stability/instability atmospheric conditions, the influence of the time-scale of the data, and the dependence of the energy balance closure on the wind direction.
Table 2. Parameters of the linear regression between the turbulent flux $(H+L E)$ and the available energy, as well as the Energy Balance Ratio (EBR), for the entire original dataset, and assuming $G^{\prime}$ and $\mathrm{R}_{n}$ underestimation. For each case the available energy considered is: $R_{n}$-G'(top line), $R_{n}-\mathrm{G}$ (middle line), and $R_{n}-\mathrm{G}-\mathrm{S}$ (bottom line).

\begin{tabular}{lccccc}
\hline $\begin{array}{l}\text { Data set } \\
\text { (half-hourly) }\end{array}$ & $n$ & Slope & $\begin{array}{c}\text { Intercept } \\
\left(\mathrm{W} \mathrm{m}^{-2}\right)\end{array}$ & $R^{2}$ & EBR \\
\hline Original & & 0.75 & 15 & 0.89 & 0.66 \\
& & 0.81 & 7 & 0.90 & 0.69 \\
& & 0.84 & 4 & 0.90 & 0.72 \\
Modified $\left(+40 \% \mathrm{G}^{\prime}\right)$ & & 0.76 & 16 & 0.88 & 0.70 \\
& 1270 & 0.83 & 8 & 0.89 & 0.74 \\
& & 0.88 & 5 & 0.89 & 0.87 \\
Modified $\left(R_{n}\right.$ calibrated) & & 0.70 & 19 & 0.89 & 0.61 \\
& & 0.75 & 12 & 0.90 & 0.65 \\
& & 0.77 & 10 & 0.90 & 0.68 \\
\hline
\end{tabular}

\subsection{Effect of systematic bias in instrumentation}

As mentioned before, some authors have reported biases/discrepancies when using a Q 7 sensor to measure net radiation. Kohsiek et al. (2007) showed an underestimation during the day by $20-40 \mathrm{~W} \mathrm{~m}^{-2}$ and overestimation at night by $10-20 \mathrm{~W} \mathrm{~m}^{-2}$, findings in line with those from Broztge and Duchon (2000). In this paper, we used the equation obtained by Cobos and Baker (2003) to recalculate the $R_{n}$ values to account for these uncertainties. Results included in Table 2 show a significant deterioration in the energy balance closure.

Also, an incomplete contact between the heat plate and the soil is possible yielding an underestimation of $G^{\prime}$. Some authors suggest that this underestimation might reach 30-50\%. In this work, an underestimation of $40 \%$ is assumed to analyse the effect of this contact loss in the energy imbalance. Results in Table 2 indicate a significant improvement in the energy closure when this hypothetical $G^{\prime}$ underestimation is considered.

\subsection{Dependence on the time of day}

Plots in Fig. 2 show the average diurnal variation of the energy balance closure in terms of the residual energy (Fig. 2a), and the energy balance ratio (Fig. 2b). The residual energy $\left(R_{n}-H-L E-G-S\right)$ exhibits a daily pattern characterised by positive values from 2:00 to approximately 18:00, and by negative values outside this time period, ranging from $60 \mathrm{~W} \mathrm{~m}^{-2}$ to $-10 \mathrm{~W} \mathrm{~m}^{-2}$. Daily pattern of $\mathrm{EBR}_{3}$ is shown in Fig. $2 \mathrm{~b}$. A quite stable value between 0.8 and 1 is maintained from 6:00 to $17: 00$, while $\mathrm{EBR}_{3}$ values are around 0.6 or below for the rest of the day, with two critical times for which EBR values fall drastically below 0.4 when net radiation becomes positive at night and negative late in the afternoon. This pattern was also observed by Oliphant et al. (2004) in a southcentral Indiana (USA) forest, with the best closure occurring 

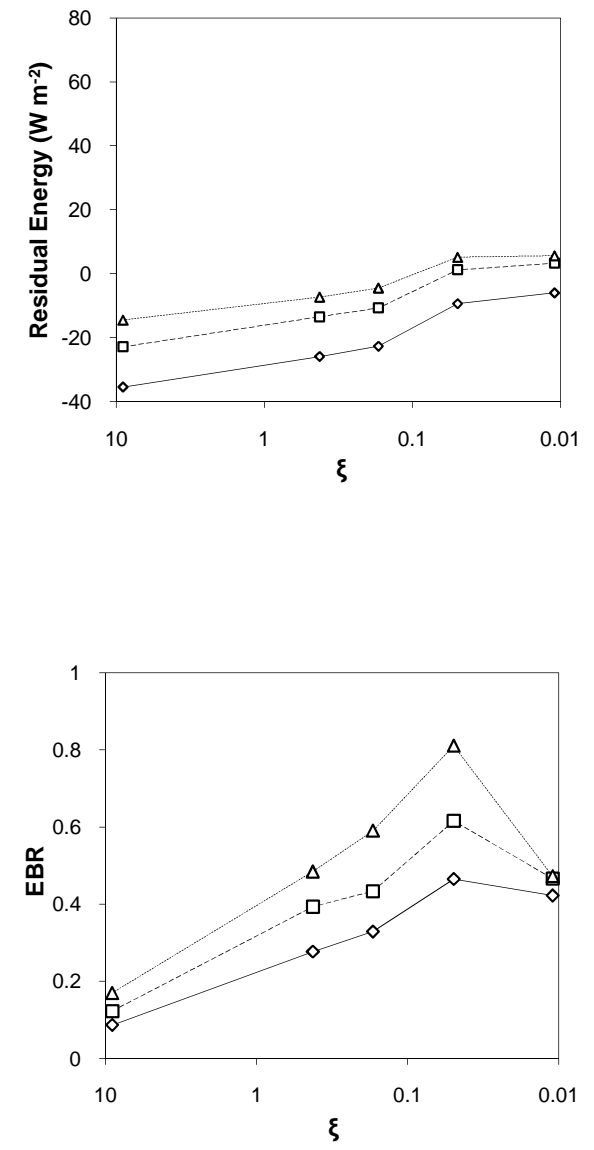

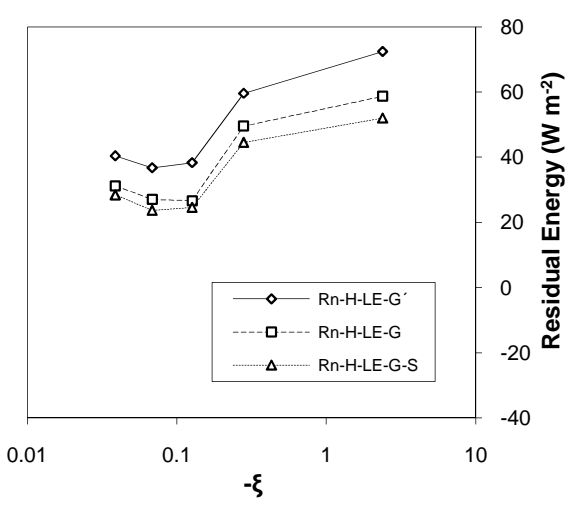

(a)

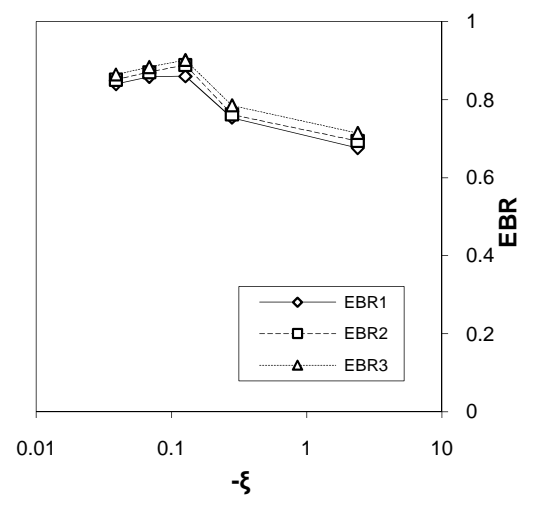

(b)

Fig. 4. Effect of the atmospheric stability $\xi$ on: (a) the residual energy, (b) the energy balance ratio. Left-hand plots correspond to stable conditions, and right-hand plots correspond to unstable conditions. Values indicate averages in each range of $\xi$.

during daylight hours, peaking shortly before sunset. Two additional curves have been also added to plots in Fig. 2, showing the results when neglecting the storage terms, and the effect of these terms on the diurnal variation of the closure can be analysed. The EC-storage has a minimum influence on the overall closure, as already seen in Fig. 1. However, note that from 20:00 to midnight the inclusion of $S$ in the energy balance yields an improvement of about 20\% in the total closure. More evident is the regulation of the closure after the inclusion of the heat storage in the soil. It basically contributes to decrease the residual energy while positive and to increase it while negative, with punctual variations reaching $40 \mathrm{Wm}^{-2}$ at some particular morning hours. In terms of the energy balance ratio, the inclusion of the heat storage in the soil improves the closure generally by increasing the EBR value, except for the time range 14:00-18:00 when it produces a decrease in the upper unity EBR values. These hours together with those from 20:00 to midnight are especially sensitive to the heat storage.

\subsection{Dependence on the friction velocity}

Low friction velocity $u^{*}$ conditions are often indicative of poorly developed turbulence. Under these conditions the eddy-covariance method is prone to underestimate the true atmospheric exchange, contributing to the imbalance of the energy budget. Different authors have shown that the closure improved when turbulent intensity increased (Barr et al., 2006; Oliphant et al., 2004; Liu et al., 2010). Figure 3 shows the dependence of the energy balance closure on the friction velocity. Average values have been plotted in intervals of $0.10 \mathrm{~m} \mathrm{~s}^{-1}$. A rapid increase of closure occurs with $u^{*}$, until values of $0.25 \mathrm{~m} \mathrm{~s}^{-1}$. Then, the increase continues but much slower. Values of EBR over 0.9 are observed when $u^{*}$ exceeds $0.80 \mathrm{~m} \mathrm{~s}^{-1}$, but a slight imbalance still remains. This dependence of EBR on $u^{*}$ is in understanding with the fact that the energy closure is better in central hours of the day when turbulence intensity is higher, and the worst closures are obtained at night when winds are usually in calm. Table 3 
Table 3. Parameters of the linear regression between the turbulent flux $(H+L E)$ and the available energy, as well as the Energy Balance Ratio (EBR), after several independent, non-cumulative filtering processes, and after all the data filtering superimposed. For each case the available energy considered is: $R_{n}-G^{\prime}$ (top line), $R_{n}-\mathrm{G}$ (middle line), and $R_{n}$-G-S (bottom line).

\begin{tabular}{llllll}
\hline Data set (half-hourly) & $n$ & Slope & $\begin{array}{l}\text { Intercept } \\
\left(\mathrm{W} \mathrm{m}^{-2}\right)\end{array}$ & $R^{2}$ & EBR \\
\hline Filtered friction velocity & 908 & 0.77 & 13 & 0.88 & 0.80 \\
$\left(\mathrm{u}^{*}<0.25 \mathrm{~m} \mathrm{~s}^{-1}\right)$ & & 0.84 & 5 & 0.88 & 0.82 \\
& & 0.85 & 4 & 0.89 & 0.85 \\
Filtered stability and neutral & 707 & 0.77 & 13 & 0.81 & 0.84 \\
conditions $(-1>\xi>-0.01)$ & & 0.84 & 5 & 0.82 & 0.84 \\
& & 0.84 & 7 & 0.83 & 0.86 \\
Filtered unfavourable wind & 900 & 0.77 & 17 & 0.90 & 0.70 \\
directions $\left(15^{\circ}>\theta>285^{\circ}\right)$ & & 0.83 & 9 & 0.91 & 0.72 \\
& & 0.86 & 6 & 0.91 & 0.77 \\
All data filtering superimposed & 459 & 0.76 & 28 & 0.81 & 0.91 \\
& & 0.82 & 20 & 0.81 & 0.92 \\
& & 0.83 & 21 & 0.82 & 0.94 \\
\hline
\end{tabular}

includes the results of energy balance closure after filtering low values of $u^{*}\left(<0.25 \mathrm{~m} \mathrm{~s}^{-1}\right)$. The energy balance ratio increases about $13 \%$. Some authors use $0.3 \mathrm{~m} \mathrm{~s}^{-1}$ (Oliphant et al., 2004) or $0.35 \mathrm{~m} \mathrm{~s}^{-1}$ (Barr et al., 2006) as a threshold for $u^{*}$. Results included in Table 3 do not change significantly when modifying this value (closure improvements lower than $2 \%$ are obtained when using 0.35 instead of 0.25 as a threshold value).

\subsection{Dependence on the stability/instability conditions}

Atmospheric stability was estimated using the stability parameter $\xi$. Figure 4 plots the energy balance closure as a function of $\xi$ in terms of both, residual energy (Fig. 4a), and energy balance ratio (Fig. 4b). Mean values were computed after segregating the data into 10 groups of 120 points each. $\xi$ values represent very stable $(\xi>1)$, stable $(0.01<\xi<1)$, neutral $(-0.01<\xi<0.01)$, unstable $(-0.01<\xi<-1)$, and very unstable $(\xi<-1)$ conditions. During stable conditions the residual energy remains below or very close to zero whereas it is positive for unstable conditions. Looking at Fig. $2 \mathrm{a}$ and in discussion above, it is evident that stable conditions occur for negative net radiation values whereas instability is the dominant condition for positive values of $R_{n}$. This different pattern between stable/unstable conditions is repeated in terms of the energy balance ratio. EBR values are generally below 0.6 for positive $\xi$ values, and above 0.7 for negative $\xi$ values. EBR peaked at $\xi$ around -0.1 , corresponding to mixed convection, with closures approaching $90 \%$. According to the defined bounds, around $10 \%$ of the data correspond to neutral atmospheric conditions, showing EBR values ranging between 0.80 and 0.70 . These results are supported by those obtained by Barr et al. (2006) at three ma- ture, boreal forest stands in central Saskatchewan, Canada, and Tanaka et al. (2008) in a young larch forest in eastern Siberia.

As already seen in Fig. 2, the effect of the inclusion of the storage terms in the energy balance is more significant during stable conditions. For $\xi$ around 0.1 , corresponding to mildly-stable conditions, the decrease in the imbalance produced by the consideration of the storage terms may reach $30 \%$. Table 3 includes the results of energy balance closure after filtering and selecting only unstable conditions $(-0.01<\xi<-1)$ from the entire dataset. The energy balance ratio increases about $14 \%$.

Note that the stability parameter, $\xi$, was obtained from the Monin-Obukov (MO) length (Garratt, 1992). Thus, an underestimation of $H$ or $L E$ might yield to a consequent underestimation of $\xi$ since a virtual heat flux density is required to estimate this MO length. For instances, a $20 \%$ underestimation in the virtual heat flux density would produce another $20 \%$ underestimation in $\xi$. The consequence would be a light lateral displacement of the plots in Fig. 4, with no effect on the main discussion above.

\subsection{Effect of the flux footprint}

The turbulent vertical flux of a constituent measured at some height above the surface represents the exchange between the atmosphere and the surface over a larger area (footprint) upwind of the measurement mast. The size of this flux footprint depends on the atmospheric stability, and the canopy structure together with the measurement height. However, the footprint of the net radiometer and storage flux observations is static (Schmid et al., 1991). According to Oliphant et al. (2004) the diameter of the net radiometer source area 
(placed at $\sim 50 \mathrm{~m}$ height) is about $150 \mathrm{~m}$. The ground area influencing the soil heat flux plates is one to several orders of magnitude smaller. However, the turbulent flux footprint may reach up to two orders of magnitude greater depending on the wind direction. This is a serious concern when validating spatially distributed surface fluxes, and one of the reasons of the increasing popularity of using large aperture scientillometers (LAS) since they are capable of obtaining spatially aggregated flux estimates, as stated in Timmermans et al. (2009). These authors applied a two-dimensional footprint approach presented by Soegaard et al. (2003) combined with the weighting function of the LAS, following Meijninger et al. (2002), to produce area-averages of fluxes suitable for validating spatially distributed models that estimate surface fluxes from remote sensing. Discrepancies were shown for some wind directions. The hypothesis of the different footprints was also considered by Su et al. (2009) to justify the observed differences between EC and LAS measurements in the framework of the EAGLE (Exploitation of AnGular effects in Land surfacE observations from satellites) 2006 campaign. Van der Kwast et al. (2009) observed very high values of sensible heat flux measured in a corn field, part of the SPARC (SPectra bARrax Campaign) 2004. The placement of the sonic anemometer on the northern edge of this corn pivot in combination with northern winds provoked the inclusion of other land covers in the footprint. Were et al. (2007) were also aware that there might be some source areas not representative of the study patches for some wind directions. Göckede et al. (2008) concluded that a footprint filter is recommended as additional information in the CarboEurope-IP database to indicate level of representativeness of each stored flux measurements. Half of the sites analyzed by Göckede et al. (2008) experienced a significant reduction in EC data quality under certain conditions.

We used equations from Schmid (1994) to determine the far end of the source area in the present work. Figure 5a shows the scheme of this fetch distance for the different wind directions. The impact of this possible mismatch in footprints was evaluated by checking the sensitivity of the energy balance closure to wind direction. Data were grouped in 12 bins of 30 degrees each, and average values of EBR were calculated. Results are plotted in Fig. 5b. EBR 3 values ranged between 0.45 and 0.85 , showing a remarkable dependence on the wind direction. A similar test was attempted by Oliphant et al. (2004), but no significant difference was shown associated with any direction. These authors focused their study in a south-central Indiana (USA) forest site, where the flux tower supporting the eddy covariance, radiation and meteorological instrumentation, was placed at an exact location with the minimum fetch of uninterrupted forest exceeding $4 \mathrm{~km}$ in any direction. The aerial picture of the SIFLEX target (Fig. 5) evidences a strong directional surface inhomogeneity. By superposing this aerial picture with the polar graph centred on the exact location of the flux tower, it can be clearly seen that the poorest closures are obtained in the

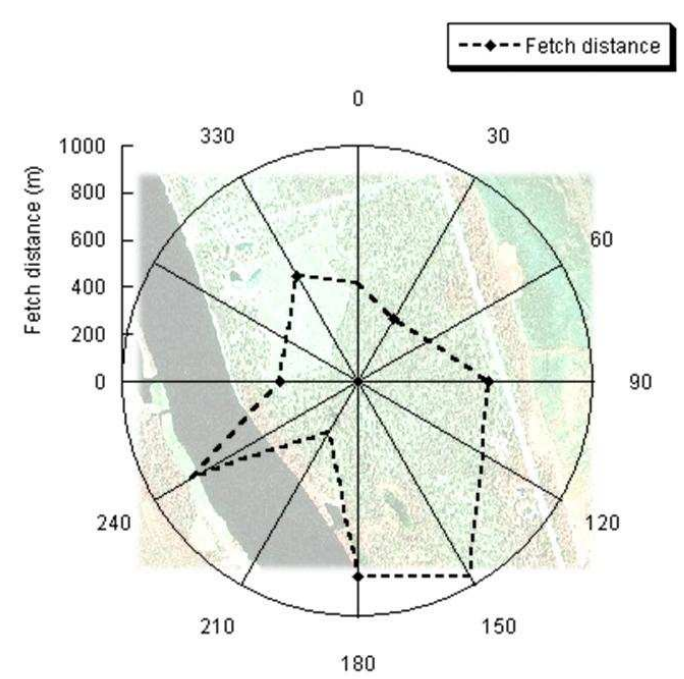

(a)

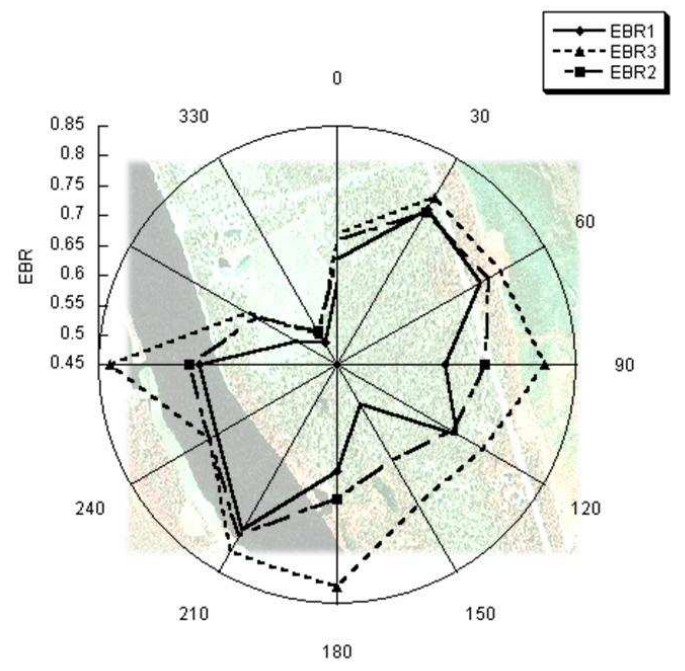

(b)

Fig. 5. Combination of an aerial view of the study site with a polar plot, centred on the location of the meteorological tower, showing the effect of the wind direction on: (a) the fetch distance, (b) the energy balance ratio. Values indicate averages in each angular range.

fourth quadrant $\left(270-360^{\circ}\right)$, with $\mathrm{EBR}_{3}$ values below 0.65 . Figure 5a indicates that the instruments are receiving turbulent flux contribution from the bare soil patch located about $100 \mathrm{~m}$ northwest of the tower. Another source of mismatch, as shown in Fig. 5a, is the presence of a river about $400 \mathrm{~m}$ southwest, which could explain the low closure, $\mathrm{EBR}_{3}=0.7$, observed at $240^{\circ}$. For the rest of wind directions $\mathrm{EBR}_{3}$ values are over 0.7. Table 3 includes the results of energy balance closure after removing wind directions located in the fourth quadrant from the entire dataset. The energy balance ratio increases about $5 \%$. 
Finally, the combined effect of all the previous error sources $\left(u^{*}, \xi\right.$, and wind direction) was evaluated. Table 3 shows the results using the 459 data remaining after the filtering process. The energy balance ratio increases about $21 \%$, reaching a value of $\mathrm{EBR}_{3}=0.94$. This is a reasonable good closure, but there is a $6 \%$ of the total energy still missing.

\subsection{Dependence on the averaging time}

Foken et al. (2006) showed that the loss of high-frequency contribution due to the finite sampling frequency can be neglected because of the very small effect on the energy imbalance. However, this is not the case with low frequency contributions. The $30 \mathrm{~min}$ averaging period appears often insufficient to include a sufficient number of the largest convective eddies to statistically resolve them (Sakai et al., 2001; Finningan et al., 2003; Foken et al., 2006; Malhi et al., 1998). A study was conducted to test the effect of the averaging time on the energy balance closure. For that, 10 days were selected with the criterion of no more than 3 gaps in the halfhourly dataset. Missing data were filled by temporal interpolation. The study of the energy balance closure was repeated as described in Sect. 3.1, but using this reduced and selected dataset instead, averaged at $30 \mathrm{~min}, 1 \mathrm{~h}, 2 \mathrm{~h}$, and 1 day. Results of this analysis are included in Table 4 . Increasing turbulent flux block averaging time from 30 to $60 \mathrm{~min}$ resulted in a small improvement in closure of $2 \%$. When the averaging time is expanded to $2 \mathrm{~h}$ the improvement in EBR resulted $5 \%$. Similar results were obtained by Oliphant et al. (2004). These authors reported a small but consistent improvement of closure (2-3\%) as a function of increasing the sampling period from 15 to $60 \mathrm{~min}$. A much larger improvement in closure, $21 \%$, is shown when daily averages are considered to estimate EBR. In addition, differences between $\mathrm{EBR}_{1}$ and $\mathrm{EBR}_{3}$ are about $7 \%$ for all the averaging time considered except the daily scale, at which the effect of including the storage terms is negligible.

Therefore, part of the $6 \%$ remaining imbalance, shown in previous section, could be justified as the impossibility of the $30 \mathrm{~min}$ averaging time to capture the low frequency flux contributions. Additional possible reason might be a systematic underestimation of the turbulent fluxes caused, for example, by vertical advection (Lee et al., 2004). Also, the inclusion of the energy storage in the canopy biomass in Eq. (1) could improve the overall closure. Wilson et al. (2002) reported, for the forested sites, an average increase of $7 \%$ in the slope of the regression when the canopy heat storage (air and biomass) was included. This increase is a $4 \%$ higher than that showed in Sect. 3.1 when only the heat storage in the air was considered. Furthermore, a recent study by Haslwanter et al. (2009) assessed the ability of the two different EC systems (open path and closed path gas analyzers) to close the energy balance. A slightly more favourable closure was observed for open path systems, which suggests that the closed path system used in this work could be an additional source
Table 4. Parameters of the linear regression between the turbulent flux $(H+L E)$ and the available energy, as well as the Energy Balance Ratio (EBR), at different time scales. For each time scale the available energy considered is: $R_{n}-\mathrm{G}^{\prime}$ (top line), $R_{n}-\mathrm{G}$ (middle line), and $R_{n}-\mathrm{G}-\mathrm{S}$ (bottom line). (Selection of 10 days).

\begin{tabular}{|c|c|c|c|c|c|}
\hline Time scale & $n$ & Slope & $\begin{array}{l}\text { Intercept } \\
\left(\mathrm{W} \mathrm{m}^{-2}\right)\end{array}$ & $R^{2}$ & EBR \\
\hline \multirow[t]{3}{*}{$30 \mathrm{~min}$} & 480 & 0.75 & 17 & 0.89 & 0.59 \\
\hline & & 0.82 & 8 & 0.90 & 0.62 \\
\hline & & 0.84 & 4 & 0.91 & 0.65 \\
\hline \multirow[t]{3}{*}{$1 \mathrm{~h}$} & 240 & 0.76 & 16 & 0.91 & 0.59 \\
\hline & & 0.83 & 6 & 0.93 & 0.61 \\
\hline & & 0.85 & 2 & 0.94 & 0.66 \\
\hline \multirow[t]{3}{*}{$2 \mathrm{~h}$} & 120 & 0.76 & 16 & 0.92 & 0.62 \\
\hline & & 0.83 & 6 & 0.94 & 0.63 \\
\hline & & 0.86 & 2 & 0.95 & 0.69 \\
\hline \multirow[t]{3}{*}{1 day } & 10 & 1.00 & -17 & 0.94 & 0.87 \\
\hline & & 1.01 & -18 & 0.94 & 0.87 \\
\hline & & 1.01 & -19 & 0.94 & 0.86 \\
\hline
\end{tabular}

of error. Future studies should then deal with these factors, setting up appropriate instrumentation to capture neglected terms, attempting to delimit potential imbalance sources.

\section{Conclusions}

This study is an analysis of the energy balance closure and the main sources of energy imbalance in a FLUXNET boreal forest site in Sodankylä, Finland. Using the entire halfhourly dataset, an average Energy Balance Ratio (EBR) of 0.72 is obtained. The inclusion of the heat storage terms in the energy budget yields an improvement of about $6 \%$ in the total closure, showing the importance of taking into account the heat storage in both, soil layer above the heat plates and canopy air, especially around sunset.

The dependence of the energy balance closure on time of day, stability/instability conditions, flux footprint, and averaging time was conducted in terms of the residual energy and the energy balance ratio. An increase of $13 \%$ in the closure is obtained when removing low friction velocity values $\left(\mathrm{u}^{*}<0.25 \mathrm{~m} \mathrm{~s}^{-1}\right)$. A similar improvement is observed when only unstable conditions $(-1<\xi<-0.01)$ are considered. The inclusion of low frequency flux contributions yields an increase of $5 \%$ in the closure when the averaging time is expanded from $30 \mathrm{~min}$ to $2 \mathrm{~h}$. All these results are in agreement with recent studies on energy balance closure.

The particular conditions of the emplacement surrounding the flux tower yield a lack of homogeneity of the turbulent fluxes footprint showing a dependence of the closure on the wind direction. An improvement of 5\% is detected after 
removing winds coming from a bare soil patch located $100 \mathrm{~m}$ to the northwest. An overall increase of $22 \%$ in the energy balance closure is finally observed after merging and filtering all unfavourable conditions. These findings reinforce the necessity of proper filtering of the flux dataset before comparison with model simulations. Even though the final value of 0.94 is a reasonable good energy closure further experiments are required to identify additional factors causing the $6 \%$ imbalance still existing.

Reducing the lack of energy balance in boreal forests might further contribute to a better understanding of their role on climate processes at a global scale due to the vast extensions of the planet that this ecosystem occupies.

Acknowledgements. This work was funded by the Science and Innovation Ministry (Project CGL2007-64666_CLI, and Juan de la Cierva Research Grant of Sánchez), Generalitat Valenciana (Project PROMETEO/2009/086), and University of Castilla-La Mancha (Project I320080568). We also thank the Finnish Meteorological Institute for processing and providing the flux data used in this study.

Edited by: Z. Su

\section{References}

Aurela, M., Tuovinen, J.-P, and Laurila, T.: Carbon dioxide exchange in a subartic peatland ecosystem in northern Europe measured by the eddy covariance technique, J. Geophys. Res., 103, 11289-11301, 1998.

Aurela, M., Laurila, T., and Tuovinen, J.-P.: Seasonal $\mathrm{CO}_{2}$ balances of a subartic mire. J. Geophys. Res., 106, 1623-1638, 2001.

Aurela, M., Laurila, T., and Tuovinen, J.-P.: Annual $\mathrm{CO}_{2}$ balance of a subartic fen in northern Europe: Importance of the winter-time efflux, J. Geophys. Res., 107, 4607, doi:10.1029/2002JD002055, 2002.

Aurela, M., Laurila, T., and Tuovinen, J.-P.: The timing of snow melt controls the annual $\mathrm{CO}_{2}$ balance in a subartic fen, Geophys. Res. Letter, 31, L16119, doi:10.1029/2004GL020315, 2004.

Barr, A. G., Morgenstern, K., Black, T. A., McCaughey, J. H., and Nesic, Z.: Surface energy balance closure by the eddycovariance method above three boreal forest stands and implications for the measurement of the $\mathrm{CO}_{2}$ flux, Agric. For. Meteorol., 140, 322-337, 2006.

Blanken, P. D., Black, T. A., Yang, P. C., Neumann, H. H., Nesic, Z., Staebler, R., den Hartog, G., and Novak, M. D., and Lee, X.: Energy balance and canopy conductance of a boreal aspen Forest: partitioning overstory and understory components, J. Geophys. Res., 102, 28915-28927, 1997.

Cava, D., Contini, D., Donateo, A., and Martano, P.: Analysis of short-term closure of the surface energy balance above short vegetation, Agric. For. Meteorol., 148, 82-93, 2008.

Culf, A. D., Foken, T., and Gash, J. H. C.: The energy balance closure problem, in: A new perspective on an iteractive system, edited by: Kabat, P., Claussen, M., Vegetation, Water, Humans and the Climate, Springer, Berlin, pp. 159-166, 2004.

Falge, E., Baldocchi, D., Olson, R. J., Anthoni, P., Aubinet, M., Bernhofer, C., Burba, G., Ceulemans, R., Clement, R., Dolman,
H., Granier, A., Gross, P., Grünwald, T., Hollinger, D., Jensen, N.-O., Katul, G., Keronen, P., Kowalski, A., Ta Lai, C., Law, B. E., Meyers, T., Moncrieff, J., Moors, E., Munger, J.W., Pilegaard, K., Rannik, Ü., Rebmann, C., Suyker, A., Tenhunen, J., Tu, K., Verma, S., Vesala, T., Wilson, K., and Wofsy., S.: Gap filling strategies for defensible annual sums of net ecosystem exchange. Agric. For. Meteorol., 107, 43-69, 2001.

Foken, T., Wimmer, F., Mauder, M., Thomas, C., and Liebethal, C.: Some aspects of the energy balance closure problem, Atmos. Chem. Phys., 6, 4395-4402, doi:10.5194/acp-6-4395-2006, 2006.

Foken, T.: The energy balance closure problem: an overview, Ecol. Appl., 18, 1351-1368, 2008.

Finnigan, J.: The storage term in eddy flux calculations, Agric. For. Meteorol., 136, 108-113, 2006.

Gao, Z., Lenschow, D. H., He, Z., and Zhou, M.: Seasonal and diurnal variations in moisture, heat and $\mathrm{CO}_{2}$ fluxes over a typical steppe prairie in Inner Mongolia, China, Hydrol. Earth Syst. Sci., 13, 987-998, doi:10.5194/hess-13-987-2009, 2009.

Garratt, J. R.: The Atmospheric Boundary Layer. Cambridge University Press, Cambridge, 316 pp., 1992.

Haslwanter, A., Hammerle, A., and Wohlfahrt, G.: Open-path vs. Closed-path eddy covariance measurements of the net ecosystem carbon dioxide and water vapour exchange: A long-term perspective, Agric. For. Meteorol., 149, 291-302, 2009.

Horst, T. W.: On frequency response corrections for eddy covariance flux measurements. Bound-Layer Meteorol., 94, 517-520, 2000.

Ibrom, A., Dellwik, E., Flyvbjerg, H., Jensen, N. O., and Pilegaard, $\mathrm{K}$.: Strong low-pass filtering effects on water vapour flux measurements with closed-path eddy covariance systems, Agric. For. Meteorol., 147, 140-156, 2007.

Lee, X. H., Yu, Q., Sun, X. M., Liu, J. D., Min, Q. W., Liu, Y. F., and Zhang, X. Z.: Micrometeorological fluxes under the influence of regional and local advection: a revisit, Agric. For. Meteorol., 122, 111-124, 2004.

Liu, S., Bai, J., Jia, Z., Jia, L., Zhou, H., and Lu, L.: Estimation of evapotranspiration in the Mu Us Sandland of China, Hydrol. Earth Syst. Sci., 14, 573-584, doi:10.5194/hess-14-573-2010, 2010.

Ma, Y., Wang, Y., Wu, R., Hu, Z., Yang, K., Li, M., Ma, W., Zhong, L., Sun, F., Chen, X., Zhu, Z., Wang, S., and Ishikawa, H.: Recent advances on the study of atmosphere-land interaction observations on the Tibetan Plateau, Hydrol. Earth Syst. Sci., 13, 1103-1111, doi:10.5194/hess-13-1103-2009, 2009.

Malhi, Y., Nobre, A. D., Grace, J., Kruijt, B., Pereira, M. G. P., Culf, A., and Scott, S.: Carbon dioxide transfer over a Central Amazonian rain forest, J. Geophys. Res., 103(24), 31593-31612, 1998.

Massman, W. J.: A simple method for estimating frequency response corrections for eddy covariance systems, Agric. For. Meteorol., 104, 185-198, 2000.

Massman, W. J. and Ibrom, A.: Attenuation of concentration fluctuations of water vapor and other trace gases in turbulent tube flow, Atmos. Chem. Phys., 8, 6245-6259, doi:10.5194/acp-86245-2008, 2008.

Meijninger, W. M. L. and de Bruin, H. A. R.: The sensible heat fluxes over irrigated areas in western Turkey determined with a large aperture scintillometer, J. Hydrol., 229, 42-49, 2000. 
McCaughey, J. H.: Energy balance storage terms in a mature mixed forest at Petawawa, Ontario - A case study. Bound-Layer Met., 31, 89-101, 1985.

McMillen, R. T.: A BASIC program for eddy correlation in nonsimple terrain, NOAA Tech. Memo. ERL ARL-147, NOAA Environ. Res. Lab., Silver Spring, Md, 1986.

McMillen, R. T.: An eddy correlation technique with extended applicability to non-simple terrain, Boundary-Layer Meteorol., 43, 213-245, 1988

Moore, C. J.: Frequency response corrections for eddy correlation systems, Bound.-Lay. Meteorol., 37, 17-35, 1986.

Moreno, J., Laurila, T., and Moya, I.: Solar Induced Fluorescence Experiment (Final Report), ESA, Noodwijk, Holland, 2002.

Oliphant, A. J., Grimmond, C. S. B., Zutter, H. N., Schmid, H. P., Su, H.-B., Scott, S. L., Offerle, B., Randolph, J. C., and Ehman, J.: Heat storage and energy balance fluxes for a temperate deciduous forest, Agric. For. Meteorol., 126, 185-201, 2004.

Oncley, S.P., Foken, T., Vogt, R., Kohsiek, W., De Bruin, H., Bernhofer, C., Christen, A., Grantz, D., LEhner, E., Liebetahl, C., Liu, H., Mauder, M., Pitacco, A., Ribeiro, L., and Weidinger, T.: The energy balance experiment EBEX-2000, Part I: Overview and energy balance, Bound.-Lay. Meteorol., 123, 1-28, 2007.

Sakai, R. K., Fitzjarrald, D. R., and Moore, K. E.: Importance of low-frequency contributions to eddy fluxes observed over rough surfaces. J. Appl. Meteorol., 40, 2178-2192, 2001.

Sánchez, J. M., Caselles, V., Niclòs, R., Coll, C., and Kustas, W. P.: Estimating energy balance fluxes above a boreal forest from radiometric temperature observations, Agric. For. Meteorol., 149, 1037-1049, 2009.

Schmid, H. P., Cleugh, H. A., Grimmond, C. S. B., and Oke, T. R.: Spatial variability of energy fluxes in suburban terrain, BoundLay. Meteorol., 54, 249-276, 1991.

Schmid, H. P.: Source areas for scalars and scalar fluxes, BoundLay. Meteorol., 67, 293-318, 1994.

Soegaard, H., Jensen, N. O., Boegh, E., Hasager, C. B., Schelde, K., and Thomsen, A.: Carbon dioxide exchange over agricultural landscape using eddy correlation and footprint modelling, Agr. Forest Meteorol., 114, 153-173, 2003.

Su, Z., Timmermans, W. J., van der Tol, C., Dost, R., Bianchi, R., Gmez, J. A., House, A., Hajnsek, I., Menenti, M., Magliulo, V., Esposito, M., Haarbrink, R., Bosveld, F., Rothe, R., Baltink, H. K., Vekerdy, Z., Sobrino, J. A., Timmermans, J., van Laake, P., Salama, S., van der Kwast, H., Claassen, E., Stolk, A., Jia, L., Moors, E., Hartogensis, O., and Gillespie, A.: EAGLE 2006 Multi-purpose, multi-angle and multi-sensor in-situ and airborne campaigns over grassland and forest, Hydrol. Earth Syst. Sci., 13, 833-845, doi:10.5194/hess-13-833-2009, 2009.

Tanaka, H., Hiyama, T., Kobayashi, N., Yabuki, H., Ishii, Y., Desyatkin, R. V., Maximov, T. C., and Ohta, T.: Energy balance and its closure over a young larch forest in eastern Siberia, Agric. For. Meteorol., 148, 1954-1967, 2008.
Timmermans, W. P., Su, Z., and Olioso, A.: Timmermans, W. J., $\mathrm{Su}, \mathrm{Z}$., and Olioso, A.: Footprint issues in scintillometry over heterogeneous landscapes, Hydrol. Earth Syst. Sci., 13, 2179 2190, doi:10.5194/hess-13-2179-2009, 2009.

Twine, T. E., Kustas, W. P., Norman, J. M., Cook, D. R., Houser, P. R., Meyers, T. P., Prueger, J. H., Starks, P. J., and Wesely, M. L.: Correcting eddy-covariance flux underestimates over a grassland, Agric. For. Meteorol., 103 (3), 279-300, 2000.

Tuovinen, J.-P., Aurela, M., and Laurila, T.: Comparison of different coordinate systems for Eddy covariance measurements. In: ACCENT-BIAFLUX Workshop 2005, Trace gas and aerosol flux measurement and techniques, Riso National Laboratory, Roskilde, Denmark, 2005.

van der Kwast, J., Timmermans, W., Gieske, A., Su, Z., Olioso, A., Jia, L., Elbers, J., Karssenberg, D., and de Jong, S.: Evaluation of the Surface Energy Balance System (SEBS) applied to ASTER imagery with flux-measurements at the SPARC 2004 site (Barrax, Spain), Hydrol. Earth Syst. Sci., 13, 1337-1347, doi:10.5194/hess-13-1337-2009, 2009.

van der Tol, C., van der Tol, S., Verhoef, A., Su, B., Timmermans, J., Houldcroft, C., and Gieske, A.: A Bayesian approach to estimate sensible and latent heat over vegetated land surface, Hydrol. Earth Syst. Sci., 13, 749-758, doi:10.5194/hess-13-749-2009, 2009.

Wen, J., Wang, L., and Wei, Z. G.: An overview of the LOess Plateau mesa region land surface process field EXperiment series (LOPEXs), Hydrol. Earth Syst. Sci., 13, 945-951, doi:10.5194/hess-13-945-2009, 2009.

Were, A., Villagarcía, L., Domingo, F., Alados-Arboledas, L., and Puigdefábregas, J.: Analysis of effective resistance calculation methods and their effect on modelling evapotranspiration in two different patches of vegetation in semi-arid SE Spain, Hydrol. Earth Syst. Sci., 11, 1529-1542, doi:10.5194/hess-11-15292007, 2007.

Wilczak, J. M., Oncley, S. P., and Stage, S. A.: Sonic anemometer tilt correction algorithms, Bound-Layer Met., 99, 127-150, 2001.

Wilson, K., Goldstein, A., Falge, E., Aubinet, M., Baldocchi, D., Berbigier, P., Bernhofer, C., Ceulemans, R., Dolman, H., Field, C., Grelle, A., Ibrom, A., Law, B. E., Kowalski, A., Meyers, T., Moncrieff, J., Monson, R., Oechel, W., Tenhunen, J., Valentini, R., and Verma, S.: Energy balance closure at FLUXNET sites, Agric. For. Meteorol., 113, 223-243, 2002.

Wu, J., Guan, D., Han, S., Shi, T., Jin, C., Pei, T., and Yu, G.: Energy Budget above a temperate mixed forest in northeastern China, Hydrol. Process., 21, 2425-2434, 2007.

Xin, X. and Liu, Q.: The Two-layer Surface Energy Balance Parameterization Scheme (TSEBPS) for estimation of land surface heat fluxes, Hydrol. Earth Syst. Sci., 14, 491-504, doi:10.5194/hess14-491-2010, 2010 